\title{
BMJ Open Communication in interdisciplinary teams: exploring closed-loop communication during in situ trauma team training
}

\author{
Maria Härgestam, ${ }^{1,2}$ Marie Lindkvist, ${ }^{3,4}$ Christine Brulin, ${ }^{1}$ Maritha Jacobsson, ${ }^{5}$ \\ Magnus Hultin ${ }^{2}$
}

To cite: Härgestam $M$, Lindkvist M, Brulin C, et al. Communication in interdisciplinary teams: exploring closed-loop communication during in situ trauma team training. BMJ Open 2013;3:e003525. doi:10.1136/bmjopen-2013003525

- Prepublication history for this paper is available online. To view these files please visit the journal online (http://dx.doi.org/10.1136/ bmjopen-2013-003525).

Received 10 July 2013

Revised 9 September 2013

Accepted 24 September 2013

\footnotetext{
${ }^{1}$ Department of Nursing, Umeå University, Umeå, Sweden

${ }^{2}$ Department of Surgical and Perioperative Sciences, Anaesthesiology and Intensive Care, Umeå University, Umeå, Sweden ${ }^{3}$ Department of Statistics, Umeå School of Business and Economics, Umeå International School of Public Health, Umeå University, Umeå, Sweden

${ }^{4}$ Department of Public Health and Clinical Medicine, Epidemiology and Global Health, Umeå University, Umeå, Sweden

${ }^{5}$ Department of Social Work, Umeå University, Umeå, Sweden
}

Correspondence to Maria Härgestam; maria.hargestam@umu.se

\author{
ABSTRACT \\ Objectives: Investigate the use of call-out (CO) and \\ closed-loop communication (CLC) during a simulated \\ emergency situation, and its relation to profession, \\ age, gender, ethnicity, years in profession, educational \\ experience, work experience and leadership style. \\ Design: Exploratory study. \\ Setting: In situ simulator-based interdisciplinary team \\ training using trauma cases at an emergency \\ department.
}

Participants: The result was based on 16 trauma teams with a total of 96 participants. Each team consisted of two physicians, two registered nurses and two enrolled nurses, identical to a standard trauma team.

Results: The results in this study showed that the use of CO and CLC in trauma teams was limited, with an average of $20 \mathrm{CO}$ and $2.8 \mathrm{CLC} /$ team. Previous participation in trauma team training did not increase the frequency of use of CLC while $\geq 2$ structured trauma courses correlated with increased use of CLC (risk ratio (RR) 3.17, $\mathrm{Cl} 1.22$ to 8.24). All professions in the trauma team were observed to initiate and terminate CLC (except for the enrolled nurse from the operation theatre). The frequency of team members' use of CLC increased significantly with an egalitarian leadership style (RR 1.14, Cl 1.04 to 1.26).

Conclusions: This study showed that despite focus on the importance of communication in terms of $\mathrm{CO}$ and CLC, the difficulty in achieving safe and reliable verbal communication within the interdisciplinary team remained. This finding indicates the need for validated training models combined with further implementation studies.

\section{INTRODUCTION}

Failure in communication as a basis for errors and patient injuries in healthcare was brought into focus by the Institute of Medicine at the end of the 1990s. ${ }^{1}$ When things go wrong, it is often a potentially preventable incident, caused by the interaction

\section{ARTICLE SUMMARY}

Strengths and limitations of this study

- The team members participated in their own roles in their standard positions at the emergency department. Efforts were made to ensure that the simulation training was as authentic as possible.

- Studying trauma care of an advanced mannequin instead of a real patient imposes limitations that could affect the authenticity of the situation.

- The limited use of call-out and closed-loop communication in the teams makes it difficult to draw general conclusions. However, this study points out important issues for further studies, which should pay attention to establishing safe forms of verbal communication and practical implementation of learning objectives for nontechnical skills in clinical practice.

of several human factors rather than the result of a single mistake by an individual. ${ }^{2-5}$ The change from reliance on vigilant healthcare providers to the systematic prevention of errors is a challenge in the future.

Deficiencies in verbal communication appear at all levels in organisations. One key element is the handover between and/or within departments. ${ }^{4-8}$ Shortcomings also occur within the interdisciplinary team where misunderstandings, language difficulties, interruptions and hesitation to speak up (against authority) have been reported. ${ }^{3} \quad 6$ 9-11 Communication has been shown to be an important prerequisite for the team's structure, collaboration and task performance. 91213

Standardised schemes of communication have been developed to achieve safe communication and reduce the risk of miscommunication resulting in team breakdowns. ${ }^{14-17}$ Experience from the field of aviation has led to major changes with the development of team training concepts to increase safety, for 
example, Crew Resource Management. ${ }^{18-20}$ Closed-loop communication (CLC), including call-out (CO), is an important part of the concept based on the assumption that safe communication in an emergency situation is achieved by standardised terminology and procedures. ${ }^{14}{ }^{15} \mathrm{CO}$ is the first verbalisation of an observation and it makes the team aware of important changes, particularly when something appears to be wrong. CLC can be described as a transmission model where verbal feedback is of great importance to ensure that the team members correctly understand the message. The communication strategy involves three steps: (1) the sender transmits a message: the $\mathrm{CO}$, (2) the receiver accepts the message and acknowledges its receipt, the checkback and (3) the sender verifies that the message has been received and interpreted correctly (ie, the loop is closed; figure 1). ${ }^{14} 21$ This advocated model assumes that communication is simple and clear. In practice, communication is more complicated and several other factors affect the transmission. ${ }^{22}{ }^{23}$ It is therefore of great importance to study if this communication model, suggested among educators, is useful in complicated practical situations.

When Bowers et $a l^{24}$ compared communication patterns among aircraft crews during simulation training, they found that high-performing teams used feedback (CLC) more frequently and repeated commands more often than low-performing teams. Similar results were found when studying teams during simulation training in cases of emergency obstetric care. Teams that described in clear terms the emergency $(\mathrm{CO})$ and used feedback (CLC) were more efficient in completing critical tasks (administering $\mathrm{Mg}$ infusion during an eclamptic event) than teams that were ambiguous in their communication. ${ }^{25}$ This highlights that CLC skills might be transferred from the training environment to clinical praxis, and that the use of CO followed by CLC probably increases patient safety. ${ }^{26}$

In addition to the fact that communication according to $\mathrm{CO}$ as well as CLC is of importance to optimise

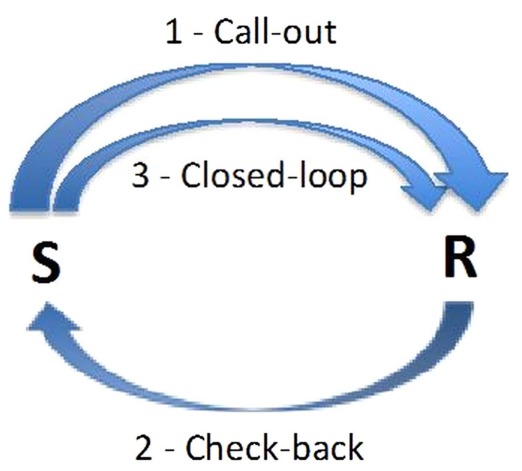

Figure 1 Description of closed-loop communication (CLC) (1). The sender (S) transmits the message, call-out (CO); the receiver $(R)$ acknowledges the message by check-back (2). The sender verifies that the message is interpreted correctly: CLC is obtained (3). patient safety, the leaders' communication styles also influence the teams' task execution. In a previous study, we showed that trauma team leaders used a mix of authoritarian and egalitarian leadership styles in order to achieve common goals. ${ }^{20}$ Leadership style determines the culture within the team and can in turn influence when and how often team members speak up when unexpected and urgent changes in a patient's condition occur. $^{11}$

In sum, in order to prevent errors in healthcare, CLC has been assumed to be a necessary component to ensure and facilitate safe team communication. ${ }^{27} 28$

Since communication is more complicated than just sending a message between individuals (see figure 1), the purpose of this exploratory study was to (1) investigate the communication during in situ trauma team training, more specifically the use of $\mathrm{CO}$ and CLC during a simulated emergency scenario and (2) its relation to profession, age, gender, ethnicity, years in profession, educational experience, work experience and leadership style.

\section{METHODS}

\section{Participants}

The participants consisted of personnel from 19 trauma teams involved in regular team training. Two of the teams were excluded from this analysis due to technical problems with the recording equipment and one team was incomplete. Thus, the reported results are based on 16 teams with 96 participants in total (surgeon $(S) n=16$, anaesthesiologist (AN) $n=16$, registered nurse (RN) $\mathrm{n}=16$, registered nurse anaesthetist (RNA) $\mathrm{n}=16$, enrolled nurse (EN) from the emergency department (ENED) $\mathrm{n}=16$ and $\mathrm{EN}$ from the operating theatre (ENOT) $\mathrm{n}=16$ ). Before the training session, the participants were informed that the recorded material would be treated in confidence and that they could leave the session whenever they wished to. Individual informed consent was obtained before the start of each training session.

\section{Research setting}

Trauma team training sessions were audio and video recorded during in situ simulator-based training in an emergency department (ED) in Northern Sweden. Efforts were made to make the simulated environment as authentic as possible; therefore, the training was executed in the regular emergency room (ER) in the ED with the trauma team composed according to the trauma team manual currently in use at the ED. An advanced patient simulator (PS) was preprogrammed to represent a severely injured patient (ISS-Injury Severity Score 25) suffering from hypovolaemia due to external trauma (SimMan 3G, Laerdal, Stavanger, Norway). Before attending the training, the participants were asked to view a $5 \mathrm{~min}$ introductory video about teamwork in emergency settings, with focus on collaboration 
and communication. In this introductory video, the importance of using CLC by giving feedback to the sender was highlighted, for example, when prescribing drugs or fluids or when asking for help with a preassigned task.

The members of the trauma team gathered in the ER when the ED alerted them to the call. The team members started to prepare the ER with equipment and materials according to the hospital's standard operating procedures for trauma care. An S or an emergency physician was the designated leader of the team and was responsible in the ER for the team's performance. An AN was in charge of assessing and maintaining the airways and breathing. An RN from the ED was responsible for inserting an intravenous line and fluids. The RNA assisted the AN with the airways and initiated the monitoring of vital parameters (ECG, blood pressure and saturation). If there was a need for another intravenous line and more fluids, the RNA inserted a second intravenous line. The ENED removed the clothing and assisted the team members with various tasks. The ENOT had no written directions but assisted the AN with the airways and the $\mathrm{S}$ with the documentation.

The ambulance personnel transported the PS from the scene of accident to the ED, and after a verbal handover from the ambulance personnel the trauma team started with the initial assessment and resuscitation. The initial assessments of the PS were based on current guidelines to identify early on life-threatening injuries according to the Advanced Trauma Life Support programme (ATLS) ${ }^{29}$ and the equivalent courses for nurses: the Trauma Nursing Core Course $(\text { TNCC })^{30}$ and Pre-Hospital Trauma Life Support (PHTLS). ${ }^{31}$ To increase the task load, systolic blood pressure was decreased to $48 \mathrm{~mm} \mathrm{Hg}$ when the PS was transferred to the stretcher. The length of the simulation scenario was designed to last for $15 \mathrm{~min}$ before the instructor interrupted the session.

\section{Data collection}

Data were collected during a period of 6 months in 2009/2010 in a hospital in Northern Sweden. Three video surveillance cameras were placed in the ER. Wireless microphones attached to each team member registered the communication between the team members. Background information about the participants was taken from questionnaires that the team members filled in before the start of the training session.

The communication in the team was transcribed and categorised using the data analysis software program NVivo V.9. The communication was then quantified as CO (only step one included) and CLC (all three steps included; figure 1), according to definitions set out in advance. ${ }^{14} 21$ The categorisation and quantifications in the total number of CLC versus CO in each team were made by two of the authors and then discussed in the research group. The number of CO and CLC initiated by the different individual team members in each team was analysed in relation to the independent variables.

Years in profession was categorised as $0-10$ and $\geq 11$ years in profession. Profession was categorised as $\mathrm{S}$ (including emergency physicians), AN, RN, RNA and EN (ENED and ENOT grouped together). Ethnicity was divided into two groups: Scandinavian and non-Scandinavian. Previous educational experience measured previous participation in (1) a structured trauma course. ATLS, TNCC and/or PHTLS and (2) a simulation training with PS. The latter variables were categorised as none, 1 course and $\geq 2$ courses/training. Previous work experience described the participant's most recent experience of trauma and the variable was categorised as no experience of trauma, most recent experience of trauma $<1$ year ago and most recent experience of trauma $\geq 1$ year ago. In order to gain an overview of leadership styles, the number of turnconstructional units of the different communication strategies used by the leader (coercive, discussing, educating and negotiating, cf. ref. 32) in each training session was counted. The variable authoritarian leadership style is the sum of coercive (orders, commands) and educating (transferring knowledge) turn-constructional units. ${ }^{20}$ Since the variable is the sum of turn-constructional units, it is a continuous variable and can vary between 0 and $\infty$. In this study, the variable authoritarian leadership style varied between 0 and 20 . The variable egalitarian leadership style is the sum of discussing (involved team members agree in the decision-making process) and negotiating (disagreements between team members in the decision-making process) turn-constructional units. ${ }^{20}$ The variable is a continuous variable, the sum of turnconstructional units, and can vary between 0 and $\infty$. In this study, the variable egalitarian leadership style varied between 2 and 16 .

\section{Statistical analysis}

Descriptive statistics are presented as the median (md) and quartiles $\left(Q_{1}, Q_{3}\right)$ for age and years in profession. Numbers of CO and CLC initiated by the individual team members in each team for each profession are presented as number (n) and percentage (\%).

Poisson regression analyses were performed to assess the impact of independent explanatory variables on the outcome variables, that is, the number of CLC and number of $\mathrm{CO}$ during each session. Poisson distribution was assumed, as the number of discrete events was rare. The fact that participants were correlated in each team presupposed an exchangeable correlation structure and the parameters were estimated by Generalised Estimating Equations. A backward elimination procedure was undertaken, starting with all six independent variables and the deleting of non-significant variables one at a time, and the final model consisted of the remaining significant variables. The results were presented by the risk ratio (RR) with $95 \% \mathrm{CI}$ and $\mathrm{p}$ values, and $\mathrm{p}<0.05$ was considered to be statistically significant. 
IBM SPSS (IBM Corp. Released 2011. IBM SPSS Statistics for Windows, V.20.0. Armonk, New York: IBM Corp.) was used for statistical analysis.

\section{RESULTS}

\section{Demographic characteristics}

Table 1 shows gender, age and years in the profession. Seven of the participants were of non-Scandinavian origin. Eight of the $\mathrm{S}$ and 11 of the ANs were residents. All RNAs had a postgraduate diploma in Specialist Nursing in Anaesthesia Care, while only three of the RNs had a postgraduate diploma (in Prehospital Emergency Care). The participants' previous education and work experience are shown in table 2.

\section{Description of CLC and CO}

In this study, $319 \mathrm{CO}$ were observed in a total of 16 trauma team training sessions resulting in 45 CLC (14\% of the total $\mathrm{CO}$ ). This translates into an average of $20 \mathrm{CO}$ and 2.8 $\mathrm{CLC} /$ team (table 3). All professions initiated $\mathrm{CO}$ and all professions except for the ENOT-initiated CLC (table 3). The frequency of initiation of CO and CLC varied between the professions, with the leader initiating the most and the ENOT the fewest.

\section{CO in relation to explanatory factors}

The final Poisson regression model with the number of CO defined as the dependent variable showed that the frequency of use of $\mathrm{CO} \quad(\mathrm{RR}=1.51)$ among team members with $\geq 11$ years in the profession had undergone a significant increase compared with those with $\leq 10$ years in the profession (table 4 ). Furthermore, team members with the most recent experience of trauma $(<1$ year ago) significantly increased the frequency of use of $\mathrm{CO}(\mathrm{RR}=1.43)$ compared with team members with no experience. Significantly more $\mathrm{CO}$ was used by the $\mathrm{S}(\mathrm{RR}=32.63)$, $\mathrm{AN}(\mathrm{RR}=17.47)$, $\mathrm{RNA}(\mathrm{RR}=8.17)$ and $\mathrm{RN}(\mathrm{RR}=5.36)$, compared with the EN.

Table 1 Description of profession, gender, age and years in profession

\begin{tabular}{lllc}
\hline & $\begin{array}{l}\text { Gender } \\
\text { male/ } \\
\text { female }(\mathbf{n} / \mathbf{n})\end{array}$ & $\begin{array}{l}\text { Age } \\
\text { median } \\
\left(\mathbf{Q}_{\mathbf{1}}, \mathbf{Q}_{\mathbf{3}}\right)\end{array}$ & $\begin{array}{l}\text { Years in } \\
\text { profession } \\
\text { median } \\
\left(\mathbf{Q}_{\mathbf{1}}, \mathbf{Q}_{\mathbf{3}}\right)\end{array}$ \\
\hline Profession & $11 / 5$ & $40(30,55)$ & $4(2,23)$ \\
AN & $10 / 6$ & $40(35,45)$ & $11(4,16)$ \\
RN & $8 / 8$ & $31(30,34)$ & $5(1,6)$ \\
RNA & $7 / 9$ & $39(34,45)$ & $10(5,16)$ \\
ENED & $2 / 14$ & $45(37,51)$ & $17(10,30)$ \\
ENOT & $2 / 14$ & $50(32,55)$ & $24(6,30)$ \\
Total & $40 / 56$ & $39(32,48)$ & $9(3,18)$ \\
\hline AN,
\end{tabular}

AN, anaesthesiologist; ENED, enrolled nurse from the emergency department; ENOT, enrolled nurse from the operating theatre; RN, registered nurse; RNA, registered nurse anaesthetist; $\mathrm{S}$, surgeon.
CLC in relation to explanatory factors

The final Poisson regression model with the number of CLC as dependent variable (table 5) showed that having a Scandinavian background meant a significant increase in frequency of the team members' use of CLC $(\mathrm{RR}=4.46)$ compared with having a non-Scandinavian background. Significantly more CLC were used by the $\mathrm{S}$ $(\mathrm{RR}=34.87), \mathrm{AN}(\mathrm{RR}=17.92)$ and RNA (RR=13.39), compared with the EN. The Poisson regression further showed that having a leader with an egalitarian leadership style meant a significant increase in the frequency of the team members' use of CLC $(R R=1.14)$, whereas having a leader with an authoritarian leadership style meant a significant decrease in the frequency of the team members' use of CLC $(\mathrm{RR}=0.85)$. Further, team members with previous experience of participating in trauma team training with PS did not use CLC more frequently than team members with no such experience. Previous experience of participating in $\geq 2$ structured trauma courses significantly increased the use of CLC $(\mathrm{RR}=3.17)$ compared with no experience of previous trauma courses.

\section{DISCUSSION}

Despite the explicit focus on the importance of communication in terms of CO and CLC, we found that the difficulty in establishing a safe and reliable form of verbal communication within the interdisciplinary team remained. We also found a limitation in the usage of CLC in the trauma teams: only one of the seven CO led to a completed CLC and less than three CLC were completed per team training session. Finally, we found that education in accordance with trauma courses increased the use of CLC.

It is interesting to note that in this study, the team members' previous experience of simulation training with PS did not serve to increase the frequency of their use of CO and CLC. Seventy-four per cent of the participants in the study had participated in previous trauma team training. Additionally, the participants had watched a video introduction to the trauma team training, where the importance of using CO and CLC in emergency situations had been emphasised. Apparently there seems to be a gap between evidence-based knowledge in using communication to obtain safety and practical implementation of the communication model in team training. Similar results were found in resuscitation teams that successfully used CLC in order to give verbal feedback in training situations, but the participants did not apply these skills in cardiac arrest situations. ${ }^{26}$ The content, didactics and learning objectives of the training in communication are important to consider when trying to remedy this. The participants' main focus in our study was on completing their assigned tasks, and communication appeared to be of minor importance. However, complex tasks require a more distinct communication, 
Table 2 Description of professions, previous educational experience and work experience

\begin{tabular}{|c|c|c|c|c|c|c|c|c|c|}
\hline & \multicolumn{6}{|c|}{ Educational experience } & \multicolumn{3}{|c|}{ Work experience } \\
\hline & \multicolumn{3}{|c|}{$\begin{array}{l}\text { Previous participation in } \\
\text { trauma team training with } \\
\text { patient simulator, } \mathrm{n}(\%)\end{array}$} & \multicolumn{3}{|c|}{$\begin{array}{l}\text { Previous participation in } \\
\text { structured trauma courses, } n \\
(\%)\end{array}$} & \multicolumn{3}{|c|}{$\begin{array}{l}\text { Most recent participation in real } \\
\text { trauma situation, } \mathbf{n}(\%)\end{array}$} \\
\hline & None & 1 & $\geq 2$ & None & 1 & $\geq 2$ & None & $<1$ year & $\geq 1$ year \\
\hline S & $6(37)$ & $6(37)$ & $4(25)$ & $1(6)$ & $11(69)$ & $4(25)$ & $6(37)$ & $6(37)$ & $4(25)$ \\
\hline AN & $1(6)$ & $6(37)$ & $9(56)$ & $3(19)$ & $10(62)$ & $3(19)$ & $1(6)$ & $9(56)$ & $6(37)$ \\
\hline $\mathrm{RN}$ & $7(44)$ & $5(31)$ & $4(25)$ & $8(50)$ & $6(38)$ & $2(12)$ & $2(12)$ & $9(56)$ & $5(31)$ \\
\hline RNA & $2(12)$ & $98(56)$ & $5(31)$ & $4(25)$ & $9(56)$ & $3(19)$ & $2(12)$ & $9(56)$ & $5(31)$ \\
\hline ENED* & $2(12)$ & $4(25)$ & $8(50)$ & $9(56)$ & $5(31)$ & - & $3(19)$ & $9(56)$ & $2(12)$ \\
\hline ENOT & 2 (12) & $10(62)$ & $4(25)$ & $7(44)$ & $9(56)$ & - & $5(31)$ & $6(37)$ & 5 (31) \\
\hline Total $^{*}$ & $20(21)$ & $40(42)$ & $34(35)$ & 32 (33) & $50(52)$ & $12(12)$ & $19(20)$ & $48(50)$ & $27(28)$ \\
\hline
\end{tabular}

${ }^{*}$ Two missing.

AN, anaesthesiologist; ENED, enrolled nurse from the emergency department; ENOT, enrolled nurse from the operating theatre; RN, registered nurse; RNA, registered nurse anaesthetist; S, surgeon.

which could be lost or misunderstood if the focus is mainly on the tasks.

Members of all the professions represented by the trauma teams initiated $\mathrm{CO}$ and the frequency of use of $\mathrm{CO}$ increased significantly with professional experience. Use of CO meant that team members were encouraged to speak up in order to make the other members aware of the completed tasks or important changes. ${ }^{33}$ When there are too many COs being sent out to no one in particular, there is a risk that the commands given will not make themselves heard in the noise, and the task will not lead to action. Directed commands were found by Siassakos $e t a l^{84}$ to be more likely to be executed, compared with commands called out 'in the air' that were less likely to lead to action. Multiple orders called out 'in the air' were also found to lead to task overload for the members of resuscitation teams, thus having a negative influence on team performance. ${ }^{26}$

All professions were observed to initiate and end a CLC (except for the ENOT). As expected, the S, as the designated trauma team leader, used CLC to a greater extent than did the other members in the team. A trauma team where all members were active and used CLC could indicate their leader as one having a more egalitarian leadership style, thus encouraging team

Table 3 Number of closed-loop communication (CLC) and call-out (CO) initiated by each profession

\begin{tabular}{lccc}
\hline Profession & CLC $\mathbf{n}(\%)$ & CO $\mathbf{n}(\%)$ & CLC/CO (\%) \\
\hline S & $21(47)$ & $151(47)$ & 14 \\
AN & $12(27)$ & $93(29)$ & 13 \\
RN & $1(2)$ & $22(7)$ & 4 \\
RNA & $10(22)$ & $43(14)$ & 23 \\
ENED & $1(2)$ & $6(2)$ & 17 \\
ENOT & - & $4(1)$ & - \\
Total & $45(100)$ & $319(100)$ & \\
\hline
\end{tabular}

AN, anaesthesiologist; ENED, enrolled nurse from the emergency department; ENOT, enrolled nurse from the operating theatre; RN registered nurse; RNA, registered nurse anaesthetist; S, surgeon. members to speak up. ${ }^{11} 35$ An authoritarian leadership style meant a less common use of CLC in the trauma teams. Speaking up is an important issue in interdisciplinary teams where power conflicts between professionals (nurses and doctors) and within professions (junior and senior doctors) can obstruct the delivery of crucial information about the patient to the team.

The RNAs were using CLC to a greater extent than the RNs during the simulation training. This might be explained by a combination of a higher level of education and experience among the RNAs in this study. Qualifying as an RNA involves an additional year of study at the university after becoming an RN. The RNAs had participated in more trauma team training with PS before this session and had also participated in more structured trauma courses.

In this study, having attended $\geq 2$ structured trauma courses were associated with a higher frequency of initiating the use of CLC. Even though it is the ABCDE principles that are trained during structured life-support courses such as ATLS, PHTLS and TNCC, repeated training might provide a solid foundation for trauma care. The observed improved performance in usage of CLC in an emergency situation after structured trauma courses might be in line with other studies showing that deliberate practice is key to excellence. ${ }^{36-38}$ Confidence in how to manage a case medically might allow for better teamwork.

Studying leadership behaviours in the operating theatre, Parker et $a p^{p 9}$ found that communication was focused at optimising technical skill performance rather than ensuring team teambuilding. Perhaps this reflects a common perception that communication is something that can be taken for granted and therefore not necessarily need to be practiced. Asymmetrical power relations in interdisciplinary teams have been discussed to influence the interaction and inhibit safety. ${ }^{3}$ In order to further investigate those factors already described as being important for team communication, the effects of gender, ethnicity and years in the profession were 
Table 4 Poisson regression with $\mathrm{CO}$ as a dependent variable, full and final model

\begin{tabular}{|c|c|c|c|c|c|c|}
\hline & \multicolumn{3}{|c|}{ CO full model } & \multicolumn{3}{|c|}{ CO final model } \\
\hline & $\overline{R R}$ & $95 \% \mathrm{Cl}$ & p Value & $\overline{\mathbf{R R}}$ & $95 \% \mathrm{Cl}$ & p Value \\
\hline \multicolumn{7}{|l|}{ Profession } \\
\hline $\mathrm{S}$ & 40.48 & (26.28 to 62.36 ) & 0.000 & 32.63 & (18.04 to 59.00 ) & 0.000 \\
\hline AN & 21.76 & (11.80 to 40.11$)$ & 0.000 & 17.47 & (8.99 to 33.94$)$ & 0.000 \\
\hline $\mathrm{RN}$ & 5.88 & (3.08 to 11.22 ) & 0.000 & 5.36 & (2.84 to 10.14$)$ & 0.000 \\
\hline RNA & 9.04 & (4.49 to 18.21 ) & 0.000 & 8.17 & (4.08 to 16.34$)$ & 0.000 \\
\hline EN & 1 & & & 1 & & \\
\hline \multicolumn{7}{|l|}{ Gender } \\
\hline Male & 0.82 & (0.56 to 1.21$)$ & 0.310 & & & \\
\hline Female & 1 & & & & & \\
\hline \multicolumn{7}{|l|}{ Ethnicity } \\
\hline Scandinavian & 1.44 & (0.82 to 2.54$)$ & 0.203 & & & \\
\hline Non-Scandinavian & 1 & & & & & \\
\hline \multicolumn{7}{|l|}{ Leadership style } \\
\hline Authoritarian & 0.99 & (0.96 to 1.04$)$ & 0.856 & & & \\
\hline Egalitarian & 1.01 & (0.97 to 1.05$)$ & 0.613 & & & \\
\hline \multicolumn{7}{|l|}{ Age } \\
\hline Years & 1.01 & (0.97 to 1.04$)$ & 0.678 & & & \\
\hline \multicolumn{7}{|l|}{ Years in profession } \\
\hline$\geq 11$ & 1.28 & (0.72 to 2.29$)$ & 0.394 & 1.51 & (1.10 to 2.06$)$ & 0.011 \\
\hline$\leq 10$ & 1 & & & 1 & & \\
\hline \multicolumn{7}{|l|}{ Trauma course } \\
\hline$\geq 2$ & 0.98 & (0.65 to 1.47$)$ & 0.925 & & & \\
\hline 1 & 0.77 & $(0.53 .1 .13)$ & 0.184 & & & \\
\hline None & 1 & & & & & \\
\hline \multicolumn{7}{|l|}{ Simulation training } \\
\hline$\geq 2$ & 1.17 & (0.85 to 1.61$)$ & 0.348 & & & \\
\hline 1 & 1.10 & (0.63 to 1.92$)$ & 0.742 & & & \\
\hline None & 1 & & & & & \\
\hline \multicolumn{7}{|c|}{ Most recent experience of trauma (years) } \\
\hline$\geq 1$ & 0.86 & $(0.47$ to 1.58$)$ & 0.656 & 0.93 & (0.60 to 1.45$)$ & 0.761 \\
\hline$<1$ & 1.33 & (0.83 to 2.14$)$ & 0.298 & 1.43 & (1.03 to 1.99$)$ & 0.034 \\
\hline None & 1 & & & 1 & & \\
\hline
\end{tabular}

studied. In this study, it was having a Scandinavian background, not one's gender or years in the profession that determined a significant increase in the team members' use of CLC. In this study, all leaders in the trauma teams spoke Swedish fluently, some leaders with an accent, which otherwise would have caused difficulties for the team members. In general, language is an important factor for gaining and keeping power in conversation, ${ }^{23}$ and a focus of research in the contexts of doctor-patient communication. ${ }^{22}$ Communication is complex and simple models might not solve the multifaceted problems faced by interdisciplinary teams. Empirical studies of interdisciplinary teams are needed in order to further study the factors influencing communication.

\section{Limitations}

Communication between trauma team members was investigated during interdisciplinary in situ team training. Efforts were made to ensure that the simulation training was as authentic as possible. The team members were acting in their own roles in their regular environment at the ED. In this study, the patient was a PS, which imposed limitations that could affect the authenticity of the situation. The study points to factors seen as important for the use of CO and CLC within trauma teams. However, the use of CO and CLC was inconsistent. The limited use of CLC makes it difficult to discuss the result in general, but indicates important issues for further studies: the difficulties in establishing a safe form of verbal communication and the implementation of objectives of non-technical skills as communication in clinical practice.

\section{CONCLUSIONS}

This study investigates the use of CO and CLC in trauma teams and factors that may help increase the use of CLC among the team members. The use of CLC was surprisingly limited, and in this study, members with previous experience of participating in trauma training did not use CLC to a greater extent than members with no previous experience. Despite efforts to emphasise the 
Table 5 Poisson regression with CLC as a dependent variable, full and final model

\begin{tabular}{|c|c|c|c|c|c|c|}
\hline & \multicolumn{3}{|c|}{ CLC full model } & \multicolumn{3}{|c|}{ CLC final model } \\
\hline & $\overline{\mathbf{R R}}$ & $95 \% \mathrm{Cl}$ & $\overline{p \text { Value }}$ & $\overline{\mathbf{R R}}$ & $95 \% \mathrm{Cl}$ & p Value \\
\hline \multicolumn{7}{|l|}{ Profession } \\
\hline S & 36.59 & (4.21 to 318.32 ) & 0.001 & 34.87 & (4.24 to 286.94 ) & 0.001 \\
\hline AN & 19.36 & (2.17 to 172.99 ) & 0.008 & 17.92 & (2.36 to 136.22 ) & 0.005 \\
\hline $\mathrm{RN}$ & 1.87 & (0.13 to 27.75$)$ & 0.649 & 1.42 & (0.09 to 23.36$)$ & 0.805 \\
\hline RNA & 17.29 & (1.89 to 158.07 ) & 0.012 & 13.39 & (1.62 to110.54) & 0.016 \\
\hline EN & 1 & & & 1 & & \\
\hline \multicolumn{7}{|l|}{ Gender } \\
\hline Male & 1.26 & (0.66 to 2.38$)$ & 0.481 & & & \\
\hline Female & 1 & & & & & \\
\hline \multicolumn{7}{|l|}{ Ethnicity } \\
\hline Scandinavian & 5.33 & (1.49 to 19.01$)$ & 0.010 & 4.46 & (1.87 to 10.65$)$ & 0.001 \\
\hline Non-Scandinavian & 1 & & & 1 & & \\
\hline \multicolumn{7}{|l|}{ Leadership style } \\
\hline Authoritarian & 0.84 & (0.76 to 0.94$)$ & 0.002 & 0.85 & (0.77 to 0.93$)$ & 0.000 \\
\hline Egalitarian & 1.61 & (1.04 to 1.31$)$ & 0.012 & 1.14 & (1.04 to 1.26$)$ & 0.007 \\
\hline \multicolumn{7}{|l|}{ Age } \\
\hline Years & 1.02 & (0.95 to 1.10$)$ & 0.53 & & & \\
\hline \multicolumn{7}{|l|}{ Years in profession } \\
\hline$\geq 11$ & 0.97 & (0.28 to 3.32$)$ & 0.96 & & & \\
\hline$\leq 10$ & 1 & & & & & \\
\hline \multicolumn{7}{|l|}{ Trauma course } \\
\hline$\geq 2$ & 2.31 & (0.70 to 7.68$)$ & 0.171 & 3.17 & (1.22 to 8.24$)$ & 0.018 \\
\hline$\overline{1}$ & 1.01 & (0.28 to 3.60$)$ & 0.991 & 1.67 & (0.38 to 3.60$)$ & 0.789 \\
\hline None & 1 & & & 1 & & \\
\hline \multicolumn{7}{|l|}{ Simulation training } \\
\hline$\geq 2$ & 0.97 & (0.41 to 2.30$)$ & 0.951 & & & \\
\hline$\overline{1}$ & 0.84 & (0.36 to 1.98$)$ & 0.686 & & & \\
\hline None & 1 & & & & & \\
\hline \multicolumn{7}{|c|}{ Most recent experience of trauma (years) } \\
\hline$\geq 1$ & 0.58 & (0.12 to 2.79$)$ & 0.494 & & & \\
\hline$<1$ & 1.18 & (0.41 to 3.44$)$ & 0.760 & & & \\
\hline None & 1 & & & & & \\
\hline
\end{tabular}

importance of communication in trauma team training, the difficulty in establishing a safe and reliable form of verbal communication in the interdisciplinary team remained. The gap observed between theoretical knowledge and practical use of the communication model emphasises the need for validated training models combined with implementation studies in trauma team training.

Acknowledgements This study was a part of Nordic Safety and Security (NSS), a collaboration between Umeå University, the Västerbotten County Council (VLL), Luleå University of Technology (LTU) and the Swedish Defence Research Agency (FOI).

Contributors $\mathrm{MHa}, \mathrm{CB}$ and $\mathrm{MHu}$ planned the initial study. All authors were involved in data analysis and in the initial drafting and finalising of the manuscript. The regression analyses were carried out by $\mathrm{MHa}$ and $\mathrm{ML}$.

Funding The NSS project was sponsored by EU regional funds (ref no. 41952) and this study was also supported in part by the Laerdal Foundation.

Competing interests None.

Ethics approval The study was approved by the Ethical Review Board in Northern Sweden, 9 June 2009 (Reg. no 09-106M).
Provenance and peer review Not commissioned; externally peer reviewed. Data sharing statement No additional data available.

Open Access This is an Open Access article distributed in accordance with the Creative Commons Attribution Non Commercial (CC BY-NC 3.0) license, which permits others to distribute, remix, adapt, build upon this work noncommercially, and license their derivative works on different terms, provided the original work is properly cited and the use is non-commercial. See: http:// creativecommons.org/licenses/by-nc/3.0/

\section{REFERENCES}

1. Kohn LT, Corrigan J, Donaldson MS. To err is human: building a safer health system. Washington, DC: National Academy Press, 2000.

2. Lingard L, Espin S, Whyte S, et al. Communication failures in the operating room: an observational classification of recurrent types and effects. Qual Saf Health Care 2004;13:330-4.

3. Sutcliffe KM, Lewton E, Rosenthal MM. Communication failures: an insidious contributor to medical mishaps. Acad Med 2004;79:186-94

4. Arora V, Johnson J, Lovinger D, et al. Communication failures in patient sign-out and suggestions for improvement: a critical incident analysis. Qual Saf Health Care 2005;14:401-7.

5. Reason J. Human error: models and management. BMJ 2000;320:768-70. 
6. Gawande AA, Zinner MJ, Studdert DM, et al. Analysis of errors reported by surgeons at three teaching hospitals. Surgery 2003;133:614-21.

7. Rabol LI, Andersen ML, Ostergaard D, et al. Descriptions of verbal communication errors between staff. An analysis of 84 root cause analysis-reports from Danish hospitals. BMJ Qual Saf 2011;20:268-74.

8. Nagpal K, Arora S, Vats A, et al. Failures in communication and information transfer across the surgical care pathway: interview study. BMJ Qual Saf 2012;21:843-9.

9. Lingard L, Whyte S, Espin S, et al. Towards safer interprofessional communication: constructing a model of "utility" from preoperative team briefings. J Interprof Care 2006;20:471-83.

10. Bergs EAG, Rutten FLPA, Tadros T, et al. Communication during trauma resuscitation: do we know what is happening? Injury 2005;36:905-11.

11. Edmondson AC. Speaking up in the operating room: how team leaders promote learning in interdisciplinary action teams. J Manage Stud 2003;40:1419-52.

12. Cooper S, Wakelam A. Leadership of resuscitation teams: "Lighthouse Leadership". Resuscitation 1999;42:27-45.

13. Mishra A, Catchpole K, Dale T, et al. The influence of non-technical performance on technical outcome in laparoscopic cholecystectomy. Surg Endosc 2008;22:68-73.

14. Burke CS, Salas E, Wilson-Donnelly K, et al. How to turn a team of experts into an expert medical team: guidance from the aviation and military communities. Qual Saf Health Care 2004;13:I96-104.

15. Salas E, Wilson KA, Murphy CE, et al. Communicating, coordinating, and cooperating when lives depend on it: tips for teamwork. Jt Comm J Qual Patient Saf 2008;34:333-41.

16. Lingard L, Espin S, Rubin B, et al. Getting teams to talk: development and pilot implementation of a checklist to promote interprofessiona communication in the OR. Qual Saf Health Care 2005;14:340-6.

17. Lingard L, Regehr G, Orser B, et al. Evaluation of a preoperative checklist and team briefing among surgeons, nurses, and anesthesiologists to reduce failures in communication. Arch Surg 2008;143:12-17; discussion 18.

18. Helmreich RL, Merritt AC, Wilhelm JA. The evolution of crew resource management training in commercial aviation. Int J Aviat Psychol 1999;9:19-32.

19. Sexton JB, Helmreich RL. Analyzing cockpit communications: the links between language, performance, error, and workload. Hum Perf Extrem Environ 2000;5:63-8.

20. Jacobsson M, Hargestam M, Hultin M, et al. Flexible knowledge repertoires; communication by leaders in trauma teams. Scand $J$ Trauma Resusc Emerg Med 2012:20:44.

21. Wilson KA, Salas E, Priest HA, et al. Errors in the heat of battle: taking a closer look at shared cognition breakdowns through teamwork. Hum Factors 2007;49:243-56.

22. Mishler EG. The discourse of medicine: dialectics of medical interviews. Norwood, NJ: Ablex, 1984.
23. Fairclough N. Language and power. London: Longman, 1989

24. Bowers CA, Jentsch F, Salas E, et al. Analyzing communication sequences for team training needs assessment. Hum Factors 1998;40:672-9.

25. Siassakos D, Bristowe K, Draycott TJ, et al. Clinical efficiency in a simulated emergency and relationship to team behaviours: a multisite cross-sectional study. Br J Obstet Gynaecol 2011;118:596-607.

26. Andersen PO, Jensen MK, Lippert A, et al. Identifying non-technical skills and barriers for improvement of teamwork in cardiac arrest teams. Resuscitation 2010;81:695-702.

27. Rall M, Gaba D. Patients simulators. In: Miller RD, Afton-Bird G, eds. Anesthesia vol 2. 6th edn. New York: Elsevier/Churchill Livingstone, 2005:xviii, 1617-3203s., lix.

28. Salas E, Sims DE, Burke CS. Is there a "big five" in teamwork? Small Group Res 2005;36:555-99.

29. American College of Surgeons Committee on Trauma. ATLS advanced trauma life support program for doctors. 7th edn. Chicago, IL: American College of Surgeons, 2004

30. Riksföreningen för sjuksköterskor inom Trauma (RST), Emergency Nurses Association. TNCC manual: trauma nursing core course. 5. suppl., ed. Bälinge: Riksföreningen för sjuksköterskor inom Trauma, 2003.

31. National Association of Emergency Medical Technicians (U.S.). Pre-Hospital Trauma Life Support Committee., American College of Surgeons. Committee on Trauma. PHTLS: prehospital trauma life support. Military 7th edn. St. Louis, MO: Mosby Jems/Elsevier, 2011.

32. Corbin JM, Strauss AL. The articulation of work through interaction. Sociol Quart 1993;34:71-83.

33. Brindley PG, Reynolds SF. Improving verbal communication in critical care medicine. J Crit Care 2011;26:155-9.

34. Siassakos D, Draycott T, Montague I, et al. Content analysis of team communication in an obstetric emergency scenario. $J$ Obstet Gynaecol 2009;29:499-503.

35. Klein KJ, Ziegert JC, Knight AP, et al. Dynamic delegation: hierarchical, shared and deindividualized leadership in extreme action teams. Adm Sci Q 2006;51:590-621.

36. Holcomb JB, Dumire RD, Crommett JW, et al. Evaluation of trauma team performance using an advanced human patient simulator for resuscitation training. J Trauma 2002;52:1078-85; discussion 85-6.

37. Lee SK, Pardo M, Gaba D, et al. Trauma assessment training with a patient simulator: a prospective, randomized study. J Trauma 2003;55:651-7.

38. Ericsson $\mathrm{K}$, Krampe R, Teschromer $\mathrm{C}$. The role of deliberate practice in the acquisition of expert performance. Psychol Rev 1993;100:363-406.

39. Parker SH, Yule S, Flin R, et al. Surgeons' leadership in the operating room: an observational study. Am J Surg 2012:204:347-54. 